\title{
O SECRETARIADO E A PRODUÇÃo TEXTUAL: A ARGUMENTAÇÃO NO GÊNERO DECLARAÇÃO
}

\section{SECRETARIAT AND TEXTUAL PRODUCTION: ARGUMENTATION IN THE TEXTUAL GENRE LETTER OF DECLARATION}

\author{
Erivaldo Pereira do Nascimento \\ Doutorado em Letras pela Universidade Federal da Paraíba - UFPB \\ erivaldo@ccae.ufpb.br
}

\author{
Raquel Ferreira da Silva \\ Graduanda em Secretariado Executivo Bilíngue pela Universidade Federal da \\ Paraíba - UFPB \\ raquelribeiro048@gmail.com
}




\section{RESUMO}

Este artigo tem como objetivo descrever a estrutura semântico-argumentativa do gênero textual/discursivo declaração, um dos documentos com o qual o profissional de Secretariado lida frequentemente. Essa investigação tem como base a Teoria da Argumentação na Língua, proposta por Ducrot $(1988,1987)$. Utilizamos também os estudos de Modalização Discursiva, proposta por Koch (2002), Castilho e Castilho (1993), Nascimento (2005), entre outros. A modalização é aqui considerada como uma estratégia semântico-argumentativa, uma vez que permite ao locutor imprimir uma avaliação ou ponto de vista sobre o conteúdo de seu enunciado, em função da interlocução. A investigação realizada a respeito do referido gênero é de natureza qualitativa e quantitativa, de cunho descritivo, e o corpus utilizado é constituído por 20 (vinte) declarações emitidas por diferentes organizações ou instituições públicas e privadas. Nas declarações analisadas percebemos que a argumentação se faz presente através dos modalizadores e operadores argumentativos, utilizados pelo locutor para imprimir diferentes efeitos de sentido nos textos.

Palavras-Chave: Redação Comercial e Oficial; Modalização; Gênero Declaração. 


\section{ABSTRACT}

This article aims at describing the semantic argumentative structure of the textual/discursive genre Letter of Declaration, one of the documents with which the executive secretary frequently deals. This investigation is based on the Argumention Theory in the Language proposed by Ducrot $(1988,1987)$. We also used the studies about Discursive Modalization proposed by Koch (2002), Castilho e Castilho (1993), Nascimento (2005), among others. Modalization is considered here as a semantic argumentative strategy, as it enables the speaker to make a statement or to express a point of view about the content of his/her enunciation, according to the interlocution. This study about the previously mentioned gender is qualitative, quantitative and descriptive. The corpus used is composed of 20 (twenty) Letters of Declaration issued by different organizations or private and public institutions. We perceived that in the Letters of Declaration analysed argumentation is achieved by the use of modalizers and argumentative operators, used by the speaker to produce different effects of meaning in the texts.

Keywords: Business and Official Writing; Modalization; Letters of Declaration. 
O secretariado e a produção textual: a argumentação no gênero declaração

\section{INTRODUÇÃO}

Esta investigação, a respeito das estratégias semântico-argumentativas do gênero declaração, tem como objetivo analisar e descrever a estrutura e o funcionamento argumentativo de declarações coletadas em instituições públicas e privadas. Trata-se de uma pesquisa ligada ao projeto intitulado "Estudos Semântico-Argumentativos de Gêneros do Discurso: redação escolar e gêneros formulaicos (ESADG)", financiado com recursos do CNPq.

A investigação se justifica pelo fato de que a produção do gênero declaração, juntamente com tantos outros que formam o conjunto dos documentos que compõem a Redação Comercial e Oficial, faz parte atividades rotineiras do Secretário, em outras palavras, é uma das atribuições desse profissional a elaboração e manuseio desse tipo de documento. Por essa razão, é de suma importância que tal profissional conheça e domine o funcionamento das estratégias argumentativas causadas pelos diversos tipos de operadores e modalizadores no referido gênero. Isso proporcionará ao Secretário uma maior compreensão dos efeitos de sentido que ele poderá causar em seus textos, e de como deve ser o seu posicionamento enquanto locutor, mediante aquilo que deseja tratar na elaboração das declarações.

O corpus da presente pesquisa é composto por 20 (vinte) declarações, que foram coletadas em diferentes instituições públicas e privadas. A pesquisa realizada é de natureza qualitativa e quantitativa, de base descritiva, com foco na análise das estratégias argumentativas presentes nos textos e os efeitos de sentido gerados a partir do uso dessas estratégias.

No entanto, neste trabalho, apresentamos a descrição de 05 (cinco) textos e quantificamos os dados mais relevantes da descrição, a fim de mostrar a frequência das estratégias argumentativas no corpus.

Destacamos que, além da modalização, que é própria da natureza das declarações (declarar é asseverar), foram encontradas marcas relevantes de operadores argumentativos.

Os Operadores Argumentativos e os Modalizadores são aqui apresentados com base dos estudos de diferentes autores: Ducrot (1988) e colaboradores, Castilho e Castilho (1993), Koch (2000), Nascimento (2005) e outros. 


\section{OS ESTUDOS DA ARGUMENTAÇÃO: DA RETÓRICA À LINGUÍSTICA}

\subsection{ARGUMENTAÇÃO NA RETÓRICA}

A retórica é o ramo do conhecimento que primeiro vai se preocupar com os estudos da argumentação. Os estudos retóricos começam na Grécia Antiga, cujo principal expoente é Aristóteles, no entanto, vamos centrar nossos estudos na Nova Retórica, de Perelman.

Perelman (1999) apresenta a distinção aristotélica entre os raciocínios dialéticos e os analíticos. Os dialéticos agem sobre opinião do auditório, com a finalidade de convencer ou persuadir, já os analíticos visam à verdade, comprovada ou demonstrada.

Após estudar os raciocínios aristotélicos, Perelman os reúne na sua teoria da argumentação, criando assim a Nova Retórica, que consiste em argumentações que visem à aceitação ou à rejeição de uma tese em debate. Para o autor (1999, p. 24), a Nova Retórica

diz respeito aos discursos dirigidos a todas as espécies de auditórios, trate-se duma turba reunida na praça pública ou duma reunião de especialistas, quer nos dirijamos a um único indivíduo ou a toda a humanidade; ela examinará inclusivamente os argumentos que dirigimos a nós mesmos, atuando numa deliberação íntima.

Nessa afirmação, o estudioso deixa claro que a argumentação, na perspectiva da Nova Retórica, está presente nas situações mais corriqueiras do nosso dia-a-dia, o público pode ser individual ou coletivo, e até mesmo quando pensamos podemos estar utilizando argumentos nos convencer de algo.

Sendo assim, o que importa para essa retórica é a possibilidade de um orador persuadir ou convencer seu público sobre algo, utilizando técnicas específicas, de acordo com cada auditório.

Perelman (1999, p. 26) critica os filósofos, afirmando que não se podem ignorar as técnicas argumentativas, ao menos que suas teses sejam incontestáveis. Para ele,

Todos os que creem poder determinar a verdade independentemente da argumentação menosprezam a retórica, que se refere a opiniões: em rigor, ela poderia servir para propagar verdades garantidas ao orador pela intuição ou pela evidência, mas não para as estabelecer. 
Mas, se não se admite que se possam fundar teses filosóficas sobre intuições evidentes, será preciso recorrer a técnicas argumentativas para as fazer prevalecer. A nova retórica torna-se, então, instrumento indispensável à filosofia.

Segundo o autor, a argumentação visa à adesão no campo das ideias ou da ação, ou seja, a intenção do orador é a de que o auditório pretendido adira a uma ideia, realize uma ação, ou crie uma predisposição para tal.

Chaim Perelman (1999) faz uma distinção entre persuasão e convencimento: a persuasão é quando se elabora um destinado a atingir um público específico, particular, e o convencimento é quando o discurso visa o auditório universal, ou seja, todo e qualquer homem de razão.

Perelman (1999, p. 54) ainda afirma que

Toda argumentação implica uma seleção de fatos e valores, a sua descrição de uma forma particular, numa certa linguagem e com uma insistência que varia consoante a importância que se Ihes confere. Escolha de elementos, escolha de um modo de descrição e apresentação, juízo de valor ou de importância, todos estes elementos são considerados tanto mais justificadamente como manifestando uma posição, quanto mais nitidamente se veja que outra escolha, outra apresentação, outro juízo de valor se Ihes poderia opor.

Para essa perspectiva, é de extrema importância que o discurso seja elaborado a partir de premissas aceitas pelo auditório. Somente assim, o orador ganhará a adesão pretendida. Não importa para a Teoria da Argumentação Retórica se as premissas são verdadeiras ou falsas, o que interessa é que sejam convincentes ou persuasivas o bastante para se ganhar a adesão do auditório.

\subsection{ARGUMENTAÇÃO NA LÍNGUA}

Ducrot (1988, p. 48) critica a Teoria da Argumentação Retórica porque esta considera a argumentação como algo exterior à língua. Segundo o autor, na concepção tradicional, a argumentação não está na língua, mas nos fatos, nas presunções etc. que se usam como premissas.

A Teoria da Argumentação na Língua, de Ducrot e colaboradores, também se opõe à concepção tradicional de sentido, postulando que nem sempre é possível distinguir e separar as três indicações de sentido tradicionalmente 
descritas no enunciado: - as objetivas, que descrevem a realidade; as subjetivas, que mostram a atitude do locutor; e as intersubjetivas, que se referem às relações locutor-receptor.

Segundo Ducrot, a função primeira da linguagem não é descrever a realidade e, se isso ocorre, é através dos aspectos subjetivos e intersubjetivos, que o autor os reúne denominando-os de valor argumentativo. Essa teoria defende que os enunciados possuem valor argumentativo no seu sentido e na sua direção: "Definido assim, no meu modo de ver, o valor argumentativo dá conta - tratarei de demonstrá-lo - dos principais efeitos subjetivos e intersubjetivos do enunciado. Considero, portanto, o valor argumentativo como o nível fundamental da descrição semântica." (Ducrot, 1988, p. 51).

Ducrot (1988, p. 52) afirma que a palavra sentido é dotada de dois aspectos, direção e significado: "Para mim, esta polissemia da palavra sentido nas línguas românicas é muito significativa: indica que o sentido de uma palavra é ao mesmo tempo uma orientação no discurso." E conclui que é essa a ideia que tenta expressar com a noção de valor argumentativo.

O autor (1988, p. 53) ainda faz uma distinção entre frase e enunciado. A frase é a estrutura abstrata do enunciado, já o enunciado constitui-se em uma manifestação da frase, aquilo que pode ser observado, são fragmentos do discurso.

Segundo Ducrot (1988, p.56), "Uma língua é um conjunto de frases. A descrição de uma frase consiste no cálculo de seu valor semântico". O discurso, por sua vez, é composto por uma sucessão de enunciados.

Para o teórico, o sentido está para o enunciado, assim como a frase está para o significado. Assim, Ducrot (1988, p.60) estabelece a diferença entre a significação da frase e o sentido do enunciado: "[...] a significação indica simplesmente o trabalho que se deve fazer para compreender o enunciado. Nesse sentido, digo que a significação é aberta. O sentido do enunciado se produz quando se obedece às indicações dadas pela significação".

A Teoria da Argumentação na Língua considera que a argumentatividade está na própria estrutura da língua, nas suas frases. Em outras palavras, a língua proporciona aos seus usuários diferentes frases e estruturas que permitem a materialização da argumentatividade, nos enunciados. 
Entre esses elementos da estrutura da língua que funcionam como estratégias argumentativas estão os operadores argumentativos, os modalizadores, os ativadores de pressuposição, entre outros.

\subsubsection{Operadores Argumentativos}

Para Koch (2000, p.30), o termo "operadores argumentativos" foi cunhado por Ducrot para denominar certos elementos da língua que têm por função indicar a força argumentativa dos enunciados, o sentido para o qual apontam.

Koch (2000) afirma que Ducrot se utiliza de duas noções básicas para explicar o funcionamento dos operadores argumentativos: as de escala argumentativa e classe argumentativa. A classe argumentativa se constitui de uma série de enunciados com argumentos que têm o mesmo peso e levam a uma mesma conclusão. Já na escala argumentativa os enunciados se apresentam em gradação de força crescente como argumentos que levam a uma determinada conclusão.

Segundo Koch (2000), os operadores argumentativos são classificados da seguinte maneira:

- operadores que assinalam o argumento mais forte de uma escala argumentativa (até, até mesmo etc.);

- operadores que somam argumentos numa classe a favor de uma mesma conclusão (e, também etc.);

- operadores que introduzem uma conclusão relativamente a argumentos de enunciados anteriores (portanto, pois etc.);

- operadores que introduzem argumentos alternativos que levam a conclusões diferentes ou opostas (ou, quer... quer etc.);

- operadores que estabelecem relações de comparação entre elementos a favor de uma determinada conclusão (mais que, menos que etc.);

- operadores que introduzem uma justificativa ou explicação relativamente ao enunciado anterior (porque, já que etc.);

- operadores que contrapõem argumentos que levam a conclusões contrárias (porém, no entanto etc.);

Koch (2000, p.36) afirma que, do ponto de vista semântico, os operadores mas e embora têm funções semelhantes: eles opõem argumentos enunciados 
de perspectivas diferentes, que levam, pois, a conclusões contrárias. Esses operadores se divergem no que diz respeito à estratégia argumentativa utilizada pelo locutor: o mas emprega a "estratégia de suspense", ou seja, orienta o interlocutor a conclusão $R$, para depois introduzir o argumento (ou conjunto de argumentos) que levam a conclusão não - $\mathrm{R}$; ao empregar o embora, o locutor utiliza a estratégia de antecipação, isto é, indica de antemão que o argumento introduzido por esse operador vai ser anulado, "não vale".

- operadores que introduzem no enunciado conteúdos pressupostos (já, ainda etc.);

- operadores que distribuem em escalas opostas, ou seja, um deles aponta para a afirmação da totalidade e o outro aponta para a negação da totalidade (um pouco, pouco, quase, apenas etc.).

Há, além desses descritos por Koch, muitos outros operadores argumentativos que estão inseridos na língua e são responsáveis pela força argumentativa dos enunciados, imprimindo neles as intenções dos locutores em relação ao conteúdo.

\subsubsection{A modalização como estratégia argumentativa}

A modalização ou modalidade é vista, neste trabalho, como uma das estratégias argumentativas que se materializa, linguisticamente, já que permite a um locutor emitir um posicionamento a respeito de seus enunciados, em função da interlocução. Segundo Koch (2002, p.72) o locutor manifesta suas intenções e atitudes perante $o$ enunciado através de diferentes atos ilocucionários de modalização.

Cervoni (1989, p.53) afirma que a noção de modalidade implica a ideia de que uma análise semântica permite distinguir, num enunciado, um dito (conteúdo proposicional) e uma modalidade (ponto de vista do locutor sobre esse conteúdo).

Para Castilho e Castilho (1993, p.217), a modalização expressa um julgamento do falante sobre o conteúdo da proposição, decorrendo daqui suas decisões sobre afirmar, negar, interrogar, ordenar, permitir, expressar a certeza ou a dúvida sobre esse conteúdo.

Castilho e Castilho (1993, p.217) afirmam que a modalização se 
O secretariado e a produção textual: a argumentação no gênero declaração

materializa no enunciado através de diferentes elementos linguísticos denominados de modalizadores - como a prosódia, os modos verbais, os verbos auxiliares como dever, poder, querer, e os verbos que constituem orações parentéticas e matrizes como achar, crer, acreditar, os adjetivos, os advérbios, os sintagmas preposicionados em função adverbial, entre outros.

Os autores Castilho e Castilho agrupam os modalizadores em três tipos: epistêmicos (asseverativos, quase-asseverativos e delimitadores), deônticos e afetivos. Nascimento (2005), por sua vez, faz uma atualização nessa nomenclatura. Como modalizadores afetivos são muito restritos à expressão de sentimentos e emoções, a denominação mais adequada e abrangente para esses modalizadores, segundo Nascimento (2005), é modalizador avaliativo, pois mais do que expressar um sentimento por parte do falante, indica um julgamento sobre o discurso e como o locutor deseja que o discurso seja lido.

Segundo a classificação de Nascimento (2010, p. 07), os tipos de modalizadores são:

Modalização Epistêmica - é aquela que expressa uma avaliação sobre o valor de verdade e as condições de verdade da proposição.

$\checkmark \quad$ Asseverativa - indica que o falante considera verdadeiro o conteúdo da proposição.

Quase-asseverativa - indica que o falante considera o conteúdo da proposição como quase certo.

$\checkmark$ Delimitadores - estabelecem os limites dentro dos quais se deve aceitar o conteúdo como certo.

Modalização Deôntica- o falante considera o conteúdo como algo que deve acontecer obrigatoriamente

$\checkmark \quad$ De obrigatoriedade - apresenta o conteúdo como algo obrigatório e que precisa acontecer.

$\checkmark$ De proibição - expressa o conteúdo como algo proibido, que não pode acontecer.

$\checkmark \quad$ De possibilidade - expressa o conteúdo como algo facultativo ou dá a permissão para que este aconteça. 
Modalização Avaliativa - indica uma avaliação ou juízo de valor da proposição e como o locutor deseja que seu discurso seja lido, excetuando-se qualquer julgamento epistêmico ou deôntico.

Ainda para Nascimento (2010), a modalização é uma estratégia argumentativa, uma vez que permite ao locutor exprimir um julgamento a respeito do seu enunciado ou da enunciação, ao mesmo tempo em que imprime um modo como esse enunciado deve ser lido por seu interlocutor, ou age em função da interlocução, muitas vezes indicando como seu interlocutor deve agir.

\section{O GÊNERO TEXTUAL DECLARAÇÃo}

Os manuais de correspondência ou de redação geralmente conceituam a declaração como a afirmação de um fato ou circunstância, o ato de denotar ou explicar alguma coisa, um manifesto de vontade por parte do declarante que pode externar-se, ou não, em forma de documento.

Segundo Medeiros (2006, p.229), "A declaração é prova escrita, documento, depoimento, explicação. Nela se manifesta uma opinião, conceito, resolução ou observação".

Segundo esse autor, "A declaração é a afirmação da existência de um fato; existência ou não de um direito" (MEDEIROS, 2006, p. 278). Ainda de acordo com Medeiros, a declaração pode ser iniciada das seguintes maneiras: "Declaro, para os devidos fins, que... Declaro para fins de prova junto ao órgão tal... Declaro, a pedido verbal de..." etc.

O Dicionário Michaelis (2009, p. 161) apresenta uma definição mais ampla para o termo Declaração:

1 Ação ou efeito de declarar. 2 Aquilo que se declara; afirmação formal; asserção explícita. 3 Documento em que se declara alguma coisa. 4 Depoimento. 5 Informação ou documento que informa a respeito de quantia, número e espécie de rendas, lucros, bens ou objetos sujeitos a impostos ou direitos: Declaração de bens. Declaração para alfândega. 6 Confissão de amor. 7 Dir Nunciação. 8 Dir Ato diplomático, pelo qual duas ou mais potências afirmam seu acordo sobre determinado assunto. 9 Inform Sentença dentro de um programa que informa o compilador ou interpretador sobre a forma, tipo e tamanho de um elemento, constante ou variável específica. 
Neste trabalho, consideramos a declaração a partir da concepção de gêneros do discurso de Bakhtin (2000), que os considera como tipos relativamente estáveis de textos (enunciados, na nomenclatura do autor). Utilizamos também os três critérios do autor para definir ou descrever um gênero: conteúdo temático, estilo e forma composicional.

$\mathrm{Na}$ declaração está expressa a vontade do declarante em afirmar algo sobre determinado assunto. Dependendo do fato ou circunstância, ela terá denominações diferentes, provenientes de sua finalidade e de seu conteúdo. Assim, é possível encontrar diferentes tipos de declaração: de guerra, de óbito, de crédito, de ausência, de direito, de renda, de princípios, de vontade etc.

Segundo Bakhtin (2000, p. 281), o conteúdo temático presente nos enunciados refere-se ao assunto que compõe o texto. No caso da declaração, o assunto veiculado é sempre uma afirmação a respeito de algo. Nesse aspecto, o locutor vai deixar sua marca ao abordar o tema, sua subjetividade em relação ao assunto. O querer-dizer, o intuito comunicativo do produtor do documento estará presente em cada palavra dita.

Para esse estudioso, os gêneros menos aptos para refletir o estilo individual são aqueles que possuem uma forma padronizada, como a declaração, o ofício etc. No entanto, mesmo em textos padronizados, é possível perceber a presença do estilo do autor. Bakhtin também afirma que todo gênero possui um estilo linguístico próprio e que para melhor se definir um gênero, inclusive os padronizados, é preciso conhecer seu estilo geral, sua natureza e sua diversidade. A declaração possui uma linguagem própria do universo comercial e oficial e a marca da modalização, além dos operadores argumentativos, é própria do seu estilo linguístico, como esta investigação se propõe a demonstrar.

A construção composicional refere-se ao fato de que todo gênero sempre possui algo que lhe é característico. Para os manuais de redação comercial e oficial, a declaração, que pode ser manuscrita ou digitada em papel ofício (com ou sem timbre), divide-se nas seguintes partes:

$1^{\circ}$ - Título: a palavra "DECLARAÇÃO", em letras maiúsculas, no alto e centro do papel;

$2^{\circ}$ - Texto: o contexto da declaração especifica a sua finalidade. No texto deve conter a identificação do emissor, o verbo declarar no presente do indicativo e na 
primeira pessoa do singular ou plural, a finalidade do documento, nome e dados de identificação do interessado e a citação do fato a ser declarado;

$3^{\circ}$ - Localidade e data;

$4^{\circ}$ - Assinatura.

Essa modalidade de documento, que é a declaração, está presente em diversas situações do cotidiano, assumindo as formas escritas ou verbais e exercendo a função de declarar ou afirmar algo de que se tem pleno conhecimento.

\section{PROCEDIMENTOS METODOLÓGICOS}

A pesquisa realizada foi de natureza descritiva, na qual foram identificados o funcionamento de diferentes estratégias semântico-argumentativas e os efeitos de sentido provocados por sua utilização no gênero estudado.

O corpus da investigação foi coletado em organizações públicas, privadas e na internet. Foram coletadas, inicialmente, 40 (quarenta) declarações, e após uma análise detalhada, selecionamos apenas 20 (vinte) declarações para compor o corpus da presente pesquisa, considerando a incidência das estratégias argumentativas. Ao término desta etapa, iniciamos as investigações e detectamos a ocorrência marcante dos modalizadores e operadores argumentativos presentes em todas as declarações.

O próximo passo foi fazer o levantamento dos diversos tipos de modalizadores; pudemos verificar a presença de todos eles (epistêmicos, deônticos e avaliativos), além dos diversos tipos de operadores argumentativos. Em seguida, analisamos o funcionamento e efeitos que cada um deles causa no texto.

Esse trabalho de análise teve como base os princípios teóricos de Perelman (1999), Ducrot e colaboradores (1988), Castilho e Castilho (1993), Nascimento (2005 e 2010) e Koch (2000), entre outros.

\section{MODALIZADORES E OPERADORES ARGUMENTATIVOS NAS DECLARAÇÕES}


A seguir, transcrevemos cinco textos originais, marcamos neles a presença dos modalizadores (em negrito) e dos operadores (em azul). Após cada texto, analisamos o funcionamento de cada um dos modalizadores e operadores marcados. Salientamos que retiramos, dos textos, o nome das pessoas envolvidas, por questões de natureza ética.

\section{Declaração no 01}

\section{Escola Municipal de Ensino Fundamental \\ Manoel Lourenço Fernandes \\ Curral de Cima - PB}

DECLARAÇÃO

Declaro para os devidos fins que a professora $X X X X X$ esteve presente a reunião com o gestor municipal de Curral de Cima a fim de tratar de assunto de interesse da classe pedagógica e por isso ausentou-se de suas atividades escolares no dia 07/07/2010.

Atenciosamente

Curral de Cima, 10 de julho de 2010.

Na declaração 01, coletada em uma escola municipal de ensino, o locutor faz uso de o verbo discendi modalizador declarar, significando afirmar, ou seja, é um modalizador do tipo epistêmico asseverativo - que expressa uma avaliação sobre o valor de verdade da proposição. O verbo se encontra na $1^{a}$ pessoa do singular, atribuindo toda a responsabilidade ao locutor responsável pelo documento, aquele que assina a declaração.

O verbo declarar está presente, praticamente, em todas as declarações, ele já é de sua natureza. Através desse modalizador, o locutor introduz todo o conteúdo do texto apresentando-o como algo certo, do qual tem conhecimento. Assim, além de afirmar que o conteúdo é verdadeiro, o locutor assume total responsabilidade pelo dito. 
Mais adiante o locutor utiliza um operador argumentativo "a fim de" que, no texto, tem a função de introduzir objetivo ou finalidade, ou seja, que a professora se reuniu com o prefeito com a finalidade de tratar de assunto de interesse da classe pedagógica.

Nessa declaração ainda encontramos mais um operador argumentativo, a expressão "por isso", através desse operador o falante direciona o discurso com um operador argumentativo que introduz justificativa ou explicação. Assim, o locutor justifica a ausência da professora em suas atividades escolares no dia 07/07/2010.

\section{Declaração no 02}

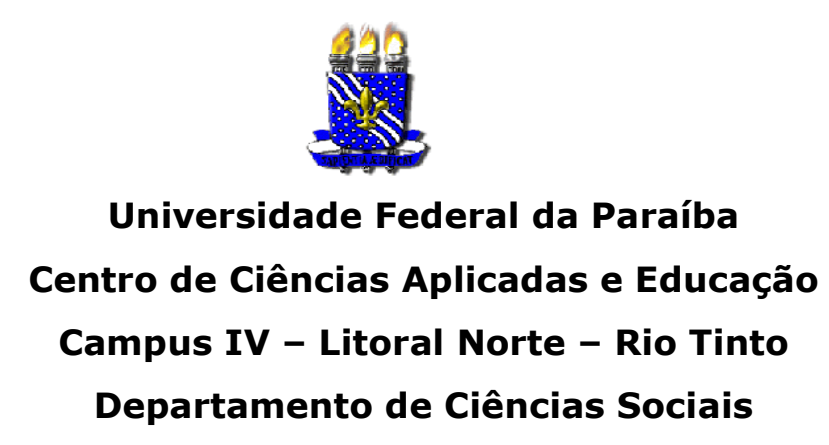

Rio Tinto, 21 de Outubro de 2010.

\section{DECLARAÇÃo}

O Departamento de Ciências Sociais, do Centro de Ciências Aplicadas e Educação da UFPB, declara: que devido à indisponibilidade momentânea de motoristas do CCAE e do período extenso de viagem, que o Professor XXX, usou veículo próprio para locomover-se até a cidade de Natal-RN, no período de 22 a 25 de setembro de 2010, para participar [...] das sessões temáticas, debates, palestras e outros eventos. Isto isenta a Instituição de possíveis danos que venham a acontecer com o veículo do proprietário.

XXX XXX XX XXX

Chefe de Departamento

Revista de Gestão e Secretariado, São Paulo, v. 2, n. 2, p.145-169, jul./dez. 2011. 
Nessa declaração observamos que há uma modalização do discurso através do verbo discendi modalizador declara, que está na terceira pessoa em uma tentativa do locutor de minimizar sua responsabilidade com 0 dito, passando-a para a instituição que representa. No entanto, o fato de ser chefe e assinar o documento, por si só, o coloca como responsável pelo discurso. Além disso, o fato de o verbo ser declarar, um modalizador Epistêmico Asseverativo, apresentando o conteúdo como verdadeiro, compromete o locutor.

Através da expressão "devido a", o falante introduz, com esse operador, uma justificativa ou explicação, ele indica o porquê de o professor ter utilizado veículo próprio para se locomover.

Mais adiante temos a expressão "indisponibilidade" que é sinônimo de não é possível que. Trata-se de um Modalizador Epistêmico quase-asseverativo, pois o locutor afirma que há indisponibilidade de motoristas, ou seja, que não é possível ter motorista. Ao dizer que é "momentâneo", ele emite um juízo de valor, justificando-se. Esse "momentâneo" funciona como Modalizador Avaliativo, porque apresenta a indisponibilidade de motoristas como algo do momento, logo passageiro.

Ainda encontramos nessa declaração a presença de mais um modalizador, a palavra "extenso". Esse adjetivo extenso é um Modalizador Avaliativo, pois revela um ponto de vista do locutor sobre o conteúdo: o falante considera o período de viagem como extenso - e isso justificaria o fato de não deslocar um motorista da instituição para realizar a viagem.

\section{Declaração n०03}

\section{Estado da Paraíba}

Prefeitura Municipal de Curral de Cima

Secretaria da Educação

\section{DECLARAÇÃo}

Declaro para os devidos fins que o aluno $X X X$, residente e domiciliado no Sítio 
Laranjeiras, s/n - zona rural, neste município, concluiu o Programa Brasil Alfabetizado no dia 05/03/2010, estando o mesmo apto a se matricular na XXX na Escola Municipal XXX, conforme encaminha a Alfabetizada do Programa XXX, XXX.

Curral de Cima, 08 de março de 2010.

$X X X X X X X X X X X X X X$

(Secretário da Educação)

Observamos, nessa terceira declaração, emitida por uma determinada instituição de ensino a certo aluno, que o locutor inicia seu discurso modalizando o enunciado através do verbo "Declaro". O locutor utiliza esse termo para expressar com toda certeza que o aluno concluiu o Programa Brasil Alfabetizado, ele afirma e se responsabiliza sozinho pelo que está dizendo, pois coloca o verbo na $1^{a}$ pessoa do singular. Trata-se de um Modalizador Epistêmico Asseverativo.

Mais adiante, nessa mesma declaração, o locutor modaliza o discurso com a expressão "apto". O locutor utiliza esse modalizador para imprimir uma avaliação ou ponto de vista. Para ele, o aluno tem plena capacidade de se matricular na citada Escola Municipal. Com isso, o locutor deixa claro que é assim que ele deseja que seu texto seja lido por seu interlocutor. Trata-se de um Modalizador Avaliativo.

Ainda nessa declaração, notamos a presença de um operador, a expressão "conforme" que funciona como operador de conformidade, indicando que um determinado fato ocorreu em consonância com outro, ou seja, apresenta um argumento baseado em outro.

Percebemos que o locutor faz uso desses modalizadores e operadores com o intuito de convencer o interlocutor de que o aluno já concluiu o Programa Educacional e está apto para se matricular na Escola Municipal determinada.

\title{
Declaração no 04
}

\section{Estado da Paraíba}

Prefeitura Municipal de Curral de Cima

Secretaria da Educação

\author{
DECLARAÇÃo
}

Revista de Gestão e Secretariado, São Paulo, v. 2, n. 2, p.145-169, jul./dez. 2011. 
Declaro para os devidos fins que XXX, funcionária pública municipal, com lotação na Secretaria da Educação, exercendo a função de Professor Classe B, esteve lecionando na Escola Municipal XXX, no dia 26 de julho do ano em curso, das 07:00 às 11:00, ficando a mesma impossibilitada de participar de outras atividades neste dia e horário.

Curral de Cima, 26 de julho de 2010.

$\mathrm{XXX} \mathrm{XXX} \mathrm{XXX} \mathrm{XX} \mathrm{XXX}$

(Secretário da Educação)

Nessa declaração, percebemos que o locutor se utiliza do verbo dicendi declarar e assim inicia modalizando o discurso como algo que deve ser lido como certo. Esse verbo discendi "Declaro" já é da natureza das declarações, pois está presente em praticamente todas elas, atribuindo total responsabilidade ao locutor que assina o documento.

Mais adiante, o locutor modaliza o discurso ao utilizar a expressão "impossibilitada", o locutor imprime uma ideia de proibição por trás da máscara de impossibilidade, pois, nesse contexto, estar impossibilitada significa que não é permitido, ou seja, que é proibido que a funcionária realize outras atividades. Aparentemente trata-se de um modalizador epistêmico asseverativo, mas, na verdade, é um modalizador deôntico de proibição, porque, nesse contexto, indica que a professora não pode participar de outras atividades nesse dia e horário.

\title{
Declaração no 05:
}

\author{
PREFEITURA MUNICIPAL DE PORTO ALEGRE \\ DEPARTAMENTO MUNICIPAL DE LIMPEZA URBANA
}

\section{DECLARAÇÃo}

Declaramos, para os devidos fins, que os resíduos sólidos caracterizados como lâmpadas fluorescentes inutilizadas são considerados resíduos perigosos, classificados como resíduos Classe I pela ABNT/NBR 10004, e como resíduos não passíveis de 
destinação a aterros sanitários municipais pela Lei Estadual xxx/1998. Portanto, em cumprimento a tais instrumentos legais e ao estipulado pela Lei Complementar Municipal xxx/1990, manejo, coleta e destinação de tais resíduos não correspondem a atribuições do DMLU, cabendo, em primeira instância, ao seu gerador.

Porto Alegre, 24 de novembro de 2003.

$X X X X X X X X X$

Diretor da Divisão de Destino Final

Na declaração de número 05, coletada pela internet, o locutor faz uso verbo discendi modalizador "declarar", significando afirmar, ou seja, é um modalizador do tipo Epistêmico Asseverativo - que expressa uma avaliação sobre o valor de verdade da proposição. O verbo se encontra na $1^{a}$ pessoa do plural "declaramos". Dessa maneira, o locutor também atribui a responsabilidade à instituição como um todo, e não apenas àquele que assina a declaração.

Ainda nessa declaração encontramos a expressão "perigosos", trata-se de um Modalizador Avaliativo, este indica que o locutor faz um juízo de valor, ou seja, ele considera que os resíduos são perigosos. Ao fazer isso, não só imprime uma avaliação sobre o dito (os resíduos), como age em função do seu interlocutor indicando como deve ser lido (como algo perigoso).

A palavra "portanto" é um operador argumentativo que introduz uma conclusão. Esse operador introduz a conclusão que os resíduos destinados a aterros sanitários municipais não são obrigações do DMLU, mas sim de seu gerador.

\section{RESULTADOS E DISCUSSÕES}

A argumentação é um processo que, através da linguagem, tem como finalidade persuadir o outro. A intenção de quem fala ou toma uma palavra, não é apenas comunicar algo, mas é levar o interlocutor a aceitar uma ideia ou ponto de vista, e assim, interferir em suas ações. Os estudos da Modalização explica que, na estruturação de um discurso, a relação entre os interlocutores é constantemente projetada através de relações de modalidade, em que o locutor 
responsável pelo discurso expressa intenções, avaliações ou atitudes perante o enunciado, conforme assinala Koch (2000).

Por meio das análises feitas no corpus investigado, foram encontrados todos os tipos de modalização (epistêmica, deôntica e avaliativa) e diversos tipos de operadores argumentativos; visualizamos como ocorrem as estratégias argumentativas no gênero declaração e percebemos que os modalizadores e operadores argumentativos estão presentes nesse gênero atuando com diferentes intenções e provocando diversos efeitos de sentido.

Com relação a modalização epistêmica, que se subdivide em três tipos, encontramos 27 casos de asseverativa, 05 de quase-asseverativa e nenhum caso de delimitadora. A modalização epistêmica asseverativa é utilizada pelo locutor para expressar certeza com relação a algum fato, isso permite que ele se comprometa totalmente com o que diz. No caso das declarações, esse tipo de modalização aparece com mais frequência no início do texto, geralmente, através dos verbos discendi declarar, sendo utilizadas para persuadir o interlocutor, ou seja, tentando convencer o interlocutor a ler aquele discurso como verdadeiro.

Encontramos o verbo declarar nas seguintes conjugações - declaro, declara e declaramos. A primeira forma do verbo declarar está na $1^{\text {a }}$ pessoa singular (presente do indicativo), representando, no texto, que o locutor se responsabiliza ele próprio por todo o discurso.

A segunda forma do verbo declarar, na $3^{a}$ pessoa do singular (presente do indicativo), tem, na declaração, a função de atribuir a responsabilidade do que está sendo declarado a uma instituição, tentando minimizar a responsabilidade de quem assina a declaração.

Já na terceira forma do verbo declarar, na $1^{\text {a }}$ pessoa do plural ( presente do indicativo), o locutor responsabiliza a si próprio mas também a instituição remetente, comprometendo a si e a outrem pelo que está sendo declarado. Trata-se, também, de uma tentativa de minimizar a responsabilidade pelo dito.

É preciso salientar que ocorrem casos em que se utiliza um modalizador epistêmico asseverativo no interior da declaração e que, geralmente, funciona com um reforço do verbo declarar presente no início do texto.

Já a modalização epistêmica quase-asseverativa foi o terceiro tipo de maior ocorrência nas declarações, 05 no total. Esses modalizadores, segundo Castilho e Castilho (1993), servem para indicar que o locutor apresenta o 
conteúdo da proposição como quase certo, ou seja, como algo que precisa de confirmação. Nesses casos, o locutor assume uma posição de distanciamento do dito; o epistêmico quase-asseverativo revela um desconhecimento por parte do locutor a respeito do objetivo de sua declaração ou do seu interlocutor. No entanto, é importante anotar que o enunciado em que esse tipo de modalizador aparece em enunciados do tipo: "a quem interessar possa". Esse enunciado já faz parte da própria estrutura composicional do documento e, por isso, não é possível afirmar se é isso realmente que ocorre, mas, pelo menos, é o que fica materializado linguisticamente.

Convém assinalar que o modalizador epistêmico delimitador não apareceu nas declarações que analisamos.

Já no caso da modalização deôntica, encontramos 4 ocorrências no corpus analisado. Esse tipo de modalização no texto adquiriu função de indicar a existência de uma obrigatoriedade ou de uma proibição por parte do locutor ou do interlocutor, com relação a uma determinado enunciado.

A modalização avaliativa é usada pelo locutor responsável pelo discurso para expressar um julgamento ou ponto de vista em relação ao que está sendo posto. Ele assume uma posição de envolvimento com o texto que está relatando, e também, determina como deseja que seu texto seja lido. Foram verificados 19 casos de modalização avaliativa, através de adjetivos como "relevante", "positiva", "infrutíferas", "abandonada", "fiel" etc.

A grande presença desses avaliativos, a segunda maior ocorrência de modalizadores, revela que o locutor não se limita a dar uma declaração sobre algo, ele também se posiciona a respeito do que está declarando, emitindo um juízo de valor e indicando como seu interlocutor deve ler o conteúdo dos seus enunciados. Dessa forma, a modalização avaliativa funciona como uma estratégia argumentativa muito peculiar no gênero declaração.

É possível observar mais detalhadamente, no quadro abaixo, o total de ocorrência dos diversos tipos de modalizadores encontrados na análise do corpus.

\begin{tabular}{|l|c|c|}
\hline \multicolumn{1}{|c|}{ Modalizadores } & Ocorrência & \% \\
\hline Epistêmicos Asseverativos & 27 & 49,1 \\
\hline Epistêmicos Quase-asseverativos & 5 & 9,1 \\
\hline
\end{tabular}


O secretariado e a produção textual: a argumentação no gênero declaração

\begin{tabular}{|l|c|c|}
\hline Deônticos de proibição & 1 & 1,8 \\
\hline Deônticos de obrigatoriedade & 3 & 5,5 \\
\hline Avaliativos & 19 & 34,5 \\
\hline Total & $\mathbf{5 5}$ & $\mathbf{1 0 0}$ \\
\hline
\end{tabular}

Dentre os tipos de operadores argumentativos, os que indicam justificativa ou explicação são os que mais aparecem nos textos - 04 ocorrências - , devido ao fato de o locutor julgar necessária uma justificativa ou explicação do que está sendo declarado. Em segundo lugar, estão os operadores que indicam conformidade - 02 ocorrências - , eles têm a intenção de indicar que algo está em consonância com outro; e os operadores que somam argumentos - 02 ocorrências - que foram utilizados para somar enunciados que expressavam declarações.

O quadro abaixo apresenta os tipos de operadores presentes no corpus, e sua ocorrência.

\begin{tabular}{|l|c|l|}
\hline Operadores Argumentativos & Ocorrência & \% \\
\hline Introduz Objetivo ou Finalidade & 1 & 8,3 \\
\hline Justificativa ou Explicação & 4 & 33,3 \\
\hline De conformidade & 2 & 16,7 \\
\hline Introduz conclusão & 1 & 8,3 \\
\hline Soma Argumentos & 2 & 16,7 \\
\hline Introduz Causa & 1 & 8,3 \\
\hline Condicionalidade & 1 & 8,3 \\
\hline Total & $\mathbf{1 2}$ & $\mathbf{9 9 , 9 = 1 0 0}$ \\
\hline
\end{tabular}

É bom assinalar que os operadores são importantes porque conduzem os movimentos argumentativos dentro do próprio texto, correlacionando os argumentos e, dessa forma, contribuem para as conclusões pretendidas, qual seja declarar ou afirmar algo a respeito de alguma coisa.

Salienta-se que a grande ocorrência de modalizadores é suficiente para afirmar que a modalização é uma estratégia do próprio gênero, principalmente a modalização epistêmica asseverativa e modalização avaliativa. E com relação aos operadores, embora ocorram em menor quantidade, também são característica 
do gênero, na medida em que correlacionam argumentos necessários (enunciados) para a declaração que se vai realizar.

Os estudos realizados sobre a Teoria da Argumentação juntamente com a Modalização nos permitiu compreender os fenômenos que ocorrem dentro do gênero declaração, deixando claro que tipos de estratégias argumentativas são utilizadas por um locutor para revelar suas intenções e posicionamentos, e também, sua maneira de agir para com seu interlocutor.

\section{CONSIDERAÇÕES FINAIS}

Ao longo da investigação visualizamos, com base na análise das declarações, que o locutor utilizou estratégias argumentativas diversas para direcionar como seu texto deveria ser lido. Com isso, o que podemos concluir a respeito de gênero textual/discursivo declaração é que, a argumentatividade e a subjetividade estão presentes nesse gênero por meio dos modalizadores e operadores argumentativos.

Já esperávamos que a presença dos modalizadores epistêmicos asseverativos fosse o tipo de maior ocorrência, com 27 casos no corpus analisado, pois já é da natureza das declarações atribuírem caráter de verdade ao seu discurso. Ficamos um tanto surpresos com a grande ocorrência dos modalizadores avaliativos. Foram 19 ocorrências nas declarações que analisamos. Ao fazer uso de tais modalizadores, o locutor utiliza estratégias argumentativas diversas para interagir com o seu interlocutor, indicando como ele deseja que seu texto seja lido, e assim atuando sobre ele.

Já os operadores argumentativos que são elementos linguísticos usados pelo locutor que têm a função de indicar a força argumentativa dos enunciados e o sentido para o qual Ihes direcionam, apareceram em menor frequência que os modalizadores, mas não menos importante. Através deles, como assinalamos anteriormente, é possível perceber o movimento argumentativo no texto, como os enunciados (argumentos) são postos a fim de uma determinada conclusão.

É de suma importância destacar que a presença dos operadores argumentativos e dos modalizadores no gênero declaração serve para negar o discurso dos manuais de redação, os quais tratam esse documento como sendo um gênero impessoal, longe de qualquer argumentatividade. No entanto, nossa 
O secretariado e a produção textual: a argumentação no gênero declaração

investigação mostrou que esses elementos linguísticos encontrados nas declarações são característicos do próprio gênero e marcam a individualidade do locutor, a qual fica registrada no texto. Com isso, podemos confirmar que ninguém fala ou escreve sem uma intenção, e essa intenção não só fica registrada no material linguístico selecionado para a interação, mas também, como afirma Ducrot (1988), já está presente na própria estrutura da língua.

Com relação às contribuições do tema abordado para a área secretarial, é importante destacar que por si só a investigação se torna relevante já que faz parte das atribuições dos profissionais de Secretariado a redação de declarações, bem como de tantos outros documentos que compõem a Redação Comercial e Oficial. Conhecer e dominar o funcionamento das estratégias argumentativas causadas pelos diversos tipos de operadores e modalizadores no referido gênero, permitirá que esse profissional, ao redigir ou utilizar-se desse documento, saiba se posicionar mediante aquilo que ele deseja comunicar em seus textos, e também saiba como agir para alcançar seus objetivos interacionais com mais eficácia.

Salientamos que, na investigação realizada, não foram encontrados casos de polifonia, por isso o foco da pesquisa foi direcionado para a ocorrência e funcionamento dos operadores argumentativos e dos modalizadores. Portanto, só é possível afirmar até o momento que, de acordo com o corpus analisado, apenas os operadores e os modalizadores são características semânticoargumentativas do gênero declaração.

\section{REFERÊNCIAS}

BAKHTIN, Mikhail. Estética da criação verbal. 3 ed. São Paulo: Martins Fontes, 2000[1895-1975].

BELTRÃO, Odacir; Correspondência, linguagem e comunicação: oficial, comercial, bancária, particular. 16 ed. São Paulo: Atlas, 1986.

BELTRÃO, Odacir; BELTRÃO, Mariúsa. Correspondência, linguagem e comunicação: oficial, comercial, bancária, particular. 23 ed. São Paulo: Atlas, 2005.

Revista de Gestão e Secretariado, São Paulo, v. 2, n. 2, p.145-169, jul./dez. 2011. 
CASTILHO, A.T.; CASTILHO, C.M.M de. Advérbios Modalizadores. IN: ILARI, Rodolfo (org) Gramática do Português Falado. Vol. II: Níveis de Análise Lingüística. 2. ed. Campinas: Editora da Unicamp, 1993.

CERVONI, Jean. A Enunciação. São Paulo: Ática, 1989.

DUCROT, Oswald. Polifonia y Argumentación: Conferencias del Seminario Teoria de la Argumentación y Análisis del Discurso. Cali: Universidad del Valle, 1988.

DUCROT, Oswald. O dizer e o dito. Revisão técnica da tradução Eduardo Guimarães. Campinas SP: Pontes, 1987.

KOCH, Ingedore Grunfeld Villaça. A Interação pela Linguagem. 5 ed. São Paulo: Contexto, 2000.

MEDEIROS, João Bosco; Correspondência: técnicas de comunicação criativa. 13

ed. São Paulo: Atlas, 1999.

- Português instrumental: para cursos de contabilidade, economia e administração. 5. ed. São Paulo: Atlas, 2005.

MEDEIROS, João Bosco; HERNANDES, Sonia. Manual da Secretária. 9 ed. São Paulo: Atlas, 2004.

NASCIMENTO, Erivaldo Pereira do. Jogando com as vozes: A polifonia - recurso modalizador - na notícia jornalística. João Pessoa. UFPB, 2005 (Tese de doutorado).

A modalização deôntica e suas peculiaridades semântico-pragmáticas. In: Fórum Linguístico. vol. 7, n. 1. Florianópolis, 2010. (pp. 30-45).

PERELMAN, Chaim. O império retórico: retórica e argumentação. 2.ed. Lisboa: Asa Editores, 1999.

Data do recebimento do artigo: $13 / 08 / 2011$

Data do aceite de publicação: 28/11/2011 